DE

M E D I C I N A

T R O P I C A L

$\mathrm{DE}$

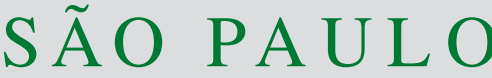

JOURNAL OF THE SÃO PAULO INSTITUTE OF TROPICAL MEDICINE

1Universidade de São Paulo, Faculdade de Medicina, São Paulo, São Paulo, Brazil

${ }^{2}$ Hospital Municipal de Santarém, Núcleo de Medicina Tropical, Santarém, Pará, Brazil

${ }^{3}$ Universidade de São Paulo, Faculdade de Medicina, Hospital das Clínicas, São Paulo, São Paulo, Brazil

Correspondence to: Vera Lúcia Teixeira de Freitas

Universidade de São Paulo, Faculdade de Medicina, Av. Dr. Eneas de Carvalho Aguiar, 470, CEP 05403-000, São Paulo, SP, Brazil

E-mail: vera_lucia@yahoo.com

Received: 31 March 2021

Accepted: 6 April 2021

\section{Suspected vertical transmission of Chagas disease caused by DTU TcIV in an infection probably transmitted orally, during anoutbreak in the Brazilian Amazon}

\author{
Vera Lúcia Teixeira de Freitas ${ }^{\circledR 1}$, Helena Rangel Esper ${ }^{1,2}$, Erika Shimoda \\ Nakanishi ${ }^{3}$ Mariana Ramos Piotto', João Guilherme Pontes Lima Assy², \\ Olívia Campos Pinheiro Berreta ${ }^{2}$, Renato do Carmo Said ${ }^{2}$, Aluisio Augusto \\ Cotrim Segurado ${ }^{1,3}$, Noemia Barbosa Carvalho ${ }^{3}$, Francisco Oscar de Siqueira \\ França ${ }^{1,3}$, Marta Heloísa Lopes ${ }^{1,3}$
}

\begin{abstract}
This study describes difficulties in the monitoring of a child born during an oral outbreak of Chagas disease, in which there are several indications that the transmission occurred through the congenital route: 1 . the mother was in the third trimester of pregnancy when she was infected; 2 . She presented high parasitemia at the time of delivery; 3 . In both, the mother and her daughter, T. cruzi was classified as DTU TcIV. The parasites were not found in the blood at birth and the infection was detected only three months later in an asymptomatic infant. As the mother and her child live in a highly endemic area, vector transmission could not be excluded during this period.
\end{abstract}

KEYWORDS: Acute Chagas disease. Child. Diagnosis. Trypanosoma cruzi. DTUs. Vertical transmission. Oral outbreak.

\section{INTRODUCTION}

Acute Chagas Disease (ACD) was reported in the Amazon Basin, where different Trypanosoma cruzi strains circulate in the transmission cycles of mammals and triatomine bugs. The population in this area is vulnerable, as it is in close contact with domestic and wild mammals, and triatomine vectors. Currently in Brazil, the majority of ACD cases are caused by intrafamily outbreaks transmitted orally after consumption of artisan foods and beverages, such as acai and the bacaba palm fruit ${ }^{1}$.

In the Northern region of Brazil, T. cruzi detection is made by direct examination of the stained thick-drop slides or blood smears. Serological methods for IgM detection were associated with clinical manifestations and epidemiological suspicion of ACD. The Polymerase Chain Reaction (PCR) presents promising results, but is routinely performed only in reference laboratories and is not available in areas where $\mathrm{CD}$ transmission is more frequent ${ }^{2}$.

In addition to these difficulties with diagnoses, $T$. cruzi parasites have many species and are highly polymorphic, presenting genotypic and phenotypic differences, being classified in six Discrete Typing Units (DTU), TcI-TcVI, and $\mathrm{TcBat}^{3}$. Previous reports suggest that genotypic and phenotypic differences, in addition to the geographical distribution of $T$. cruzi strains, can be associated with the variation in sensitivity of parasitological and serological tests ${ }^{3-5}$. The genetic diversity of T. cruzi has been reported as a possible predisposing factor for vertical transmission, due to distinct parasitemia levels; however, all Tc DTUs, with the 
exception of DTU TcIV, have been reported in congenital infections ${ }^{6}$.

This report describes a $T$. cruzi infection by DTU TcIV in a young pregnant woman and her newborn child, in whom vertical transmission could not be proven, but was suspected.

\section{CASE REPORT}

This study was approved by the Ethical Committee of the Faculdade de Medicina of the Universidade de Sao Paulo (approval $\mathrm{N}^{\circ}$ 2695.519). Written informed consent was obtained from adult patients and from parents/guardians on behalf of all the participant children.

An 18-year-old-pregnant woman from the Riverside Community of Marimarituba, municipality of Santarem (Para State), Brazil, was admitted to Santarem Municipal Hospital in April 2016 reporting one week of daily fever, myalgia, and two days of diarrhea with peripheral edema. T. cruzi trypomastigotes were found in a blood smear; she was likely infected twenty-three days before hospitalization, when she consumed "bacaba palm fruit wine". The mother's blood exams revealed lymphopenia and plaquetopenia, while the biochemical exams, chest X-ray, and electrocardiogram were normal. The serological tests showed showed a positive indirect immunofluorescence (IF) test with titers of anti-T. cruzi $\operatorname{IgG}$ and $\operatorname{IgM}$ antibodies of $1 / 320$ and $1 / 160$, respectively, a positive indirect hemagglutination test (IHAT) and a non-reagent ELISA. Quantitative PCR (qPCR) for T. cruzi detection was performed with Tcz 3/4 primers, using a previously described methodology ${ }^{7}$. A burden of 53.51 parasites $\mathrm{Eq} / \mathrm{mL}$ of blood was found.

After a spontaneous labor, a vaginal delivery occurred six days after the mother arrived at the hospital, at 34 weeks and 3 days of gestational age, according to the USG exam. The newborn weighed $2.570 \mathrm{~kg}$, had an Apgar score of 9 and 8 in the $1^{\text {st }}$ and $5^{\text {th }}$ min of life, respectively and the physical examination was normal, with no parasitemia observed by direct microscopy of peripheral blood. The female child remained asymptomatic and three months later, a new blood smear was positive by direct microscopy, in association with a qPCR detection of 78.3 parasites in $\mathrm{Eq} / \mathrm{mL}$ of blood. The infant was hospitalized, and her total blood count showed lymphocytosis; biochemistry, chest $\mathrm{X}$-ray, electrocardiogram and echocardiogram were all normal. The infant was exclusively breastfed during these three months and she was treated with benznidazole for 60 days $(5 \mathrm{mg} / \mathrm{kg} /$ day $)$. After 6 months of treatment, a new serology was performed with negative ELISA IgG and IHAT results.

The mother's treatment with benznidazole $(5 \mathrm{mg} / \mathrm{kg} /$ day for 60 days) was initiated soon after delivery, and continued during the lactation period. The mother's serology was repeated 8 months after the end of treatment and ELISA $\mathrm{IgG}$ and IHAT remained negative.

T. cruzi was genotyped by two parasite genomic sequences: the D7 divergent domain of the 24S $\alpha$ rRNA (24S $\alpha$ rRNA) and a spliced leader intergenic region (SL-IR). To this end, nested and multiplex PCR were performed as previously described ${ }^{7}$. The reference strains used in this study are described in Table 1. In the mother and the child, amplicons of $120 \mathrm{pb}$ and $150 \mathrm{pb}$ (Figure 1) were observed in 24S $\alpha$ rRNA (Figure 1A) and SL-IR (Figure 1B) PCR assays, respectively, corresponding to DTU TcIV.

\section{DISCUSSION}

This report describes a $T$. cruzi infection by DTU TcIV in a young pregnant woman with suspected vertical transmission of Chagas disease to her child. Congenital transmission could not be definitively proven, although there were several indications that the transmission took place via the congenital route:

Table 1 - Description of Trypanosoma cruzi and Trypanosoma rangeli reference strains used in this study: gene sequences GenBank accession numbers, and the molecular weight of PCR products (in bp) of T. cruzi DTUs.

\begin{tabular}{cccccc}
\hline Species & Sample ID & DTU & GeneBank accession & \multicolumn{2}{c}{ Sequence base pairs } \\
\cline { 4 - 5 } number & & HQ604893.1 & 110 & 24S $\alpha$ rRNA \\
\hline & JRcl4 & Tc I & AF301912 & 125 & 200 \\
& Y & Tc II & AF303060 & 110 & 250 \\
& MT3663 & Tc III & AY491761 & 120 or 130 & 150 \\
& JJ & Tc IV & FJ555614 & 110 and 125 & 250 \\
& Bertha & Tc V & AF245383 & 125 & 250 \\
& CL Brenner & Tc VI & KT327329 & & 250 \\
\hline T. rangeli & Tc Bat & & JF421351 & & 100 \\
\hline
\end{tabular}


(A)

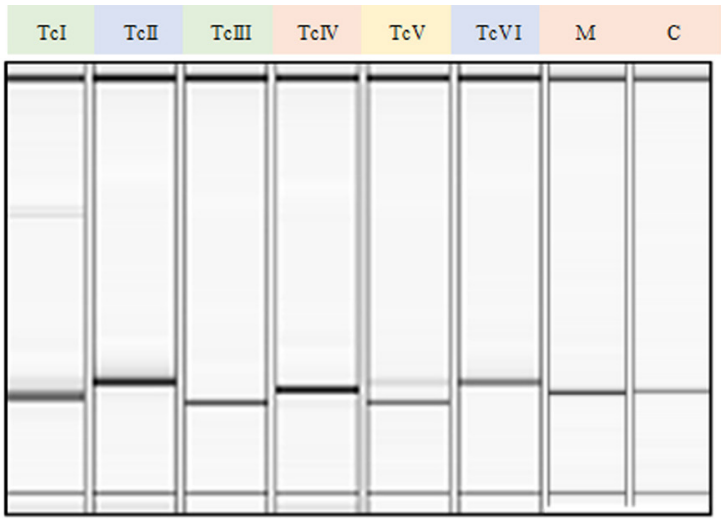

(B)

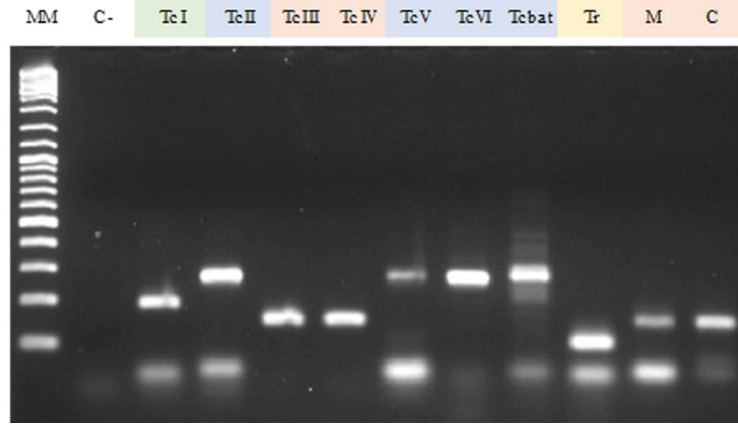

Figure 1 - Genotyping patterns of $T$. cruzi sequences 24S $\alpha$ rRNA (A) and SL-IR (B). Reference strains: Tcl - JR cl4; Tcll - Y; TcIII - MT366; TcIV - JJ; TcV - Bertha; TcVI - CL Brener; Tc bat - 1994; Tr (T.rangeli) - Tra 1719. MM: Molecular Marker 100pb; C-: Negative control; Mother (M) and Child (C).

- The mother was in the third trimester when she was infected, and she presented with a high parasite load at delivery. Some reports demonstrated an increase in maternal parasitemia during the third trimester of pregnancy with levels over 25.8 parasites in Eq/mL, increasing the risk of vertical transmission ${ }^{8,9}$.

- Breastfeeding transmission, although possible, has not been proven so far. Data on T. cruzi transmission through breastfeeding are scarce, and are mainly from animal studies. In one rare human study, 100 samples of breast milk from 78 women with $\mathrm{CD}$ did not detect any transmission in a total of 97 infants $^{10}$.

- Both in mother and the child, DTU TcIV was identified. Despite this finding, it was not possible to prove the vertical transmission, so the child returned with her mother to the endemic area where they live; yet, we still cannot exclude a vector transmission. In the Amazon basin, DTU TcIV is detected among non-human primates, in vectors, and is also associated with human infections ${ }^{11,12}$

The congenital transmission, though probable, was not confirmed. Indeed, parasites were not found in the infant's blood at birth, and infection was detected only three months later in an asymptomatic infant. Despite being a preterm newborn (congenital T. cruzi infection can result in premature birth), the newborn appeared healthy at birth, with no signs of infection. As with most infected children, 60 to $90 \%$ are asymptomatic, with mothers not seeing the need for a medical intervention ${ }^{13}$. The lack of access to health professionals in the region (with expansive size and hydrography), along with economic issues to get access to health centers, tend to create difficulties in an adequate follow-up of newborns.

The failure to detect parasites in $T$. cruzi-infected newborns in the first month of life could be attributed to the low sensitivity of the assay. Some reports demonstrated a $68.9 \%$ sensitivity in detecting T. cruzi in 267 children up to five months of age, with a $44 \%$ positivity in the first month. Children born to mothers with ACD must be followed for 12 months $^{14}$.

Based on reports fromclinical trials conducted in nonendemic areas of Spain, PCR proved to be a useful tool in detecting T. cruzi in the first month of life, and in children born to mothers with Chagas disease ${ }^{15}$. In endemic areas, where transmission still occurs with different DTUs of T. cruzi, no molecular methods of diagnosis are routinely available. Despite the need, PCR is restricted to research centers.

The global rate of vertical transmission observed in the American Continent is $2 \%$. Argentina and Bolivia concentrate most of the analyzed studies s and are the South American countries present the highest transmission rates, of $7 \%$ and $5 \%$, respectively ${ }^{16}$.

Carlier et al. ${ }^{17}$ reported that mother-to-child transmission of $\mathrm{CD}$ can occur in infected women living in Latin America (LA) or outside LA if they have previously lived in an endemic area of LA and/or were born in LA. In non-endemic areas, the global rate of Chagas disease is $3.8 \%$ among pregnant women, and the rate of congenital transmission is $2.8 \%$. Most of the data available are from Spain, the second country in the world with the largest number of immigrants from Latin America ${ }^{18}$.

In Brazil, in a systematic review with data from 1984-2009 collected in the South, Southeast and Midwest regions, indicated a pooled congenital transmission rate of $1.7 \%$. The estimated rate decreased over time from $2.3 \%$ between 1990 to 1999 to $0.2 \%$ after $2000^{19}$. However, it is important to note that the studies focused on some regions: Midwest, South and Southeast. There are no reports on the vertical transmission of Chagas disease in the Northern region, but this is the region with the highest number of notifications of acute cases of Chagas disease in the country, 2,889 cases between 2013 and 2019 or approximately 222 cases per year ${ }^{20}$.

Limitations of diagnostic tests and the absence of symptoms (or the presence of non-specific symptoms) tend 
to lead to the underreporting of DCA and of congenital transmissions and the treatment effectiveness and DCA prognosis depend on the early and accurate diagnosis of the infections.

\section{ACKNOWLEDGMENTS}

We thank the patients who provided blood samples and the medical doctors specialized in Tropical Diseases who, through an agreement signed between the Secretaria Municipal de Saude de Santarem/PA and the Nucleo de Medicina Tropical of the Departamento de Molestias Infecciosas e Parasitarias of the Faculdade de Medicina of the Universidade de Sao Paulo (DMIP FMUSP) NUMETROP followed the patients.

\section{AUTHORS' CONTRIBUTIONS}

VLTF and HRE conceptualized and designed the study; JGPLA, OCPB, RCS, NBC, designed the data collection instruments, collected data, carried out the initial analyses; EYSN and MRP, carried out the molecular assays and the initial analyses; AACS, FOSF, and MHL coordinated and supervised data collection, have written and critically reviewed the manuscript. All authors reviewed and approved the final manuscript as submitted and agreed to be accountable for all aspects of the study.

\section{CONFLICT OF INTERESTS}

The authors have no conflict of interests to disclose.

\section{FUNDING}

No specific funding was secured for this study.

\section{REFERENCES}

1. Brasil. Ministério da Saúde. Secretaria de Vigilância em Saúde. Coordenação-Geral de Desenvolvimento da Epidemiologia em Serviços. Guia de vigilância em saúde: volume único. $2^{\mathrm{a}}$ ed. Brasília: Ministério da Saúde; 2017. [cited 2021 Apr 29]. Available from http://portalarquivos.saude.gov.br/images/ pdf/2017/outubro/06/Volume-Unico-2017.pdf

2. Dias JC, Ramos Jr AN, Gontijo ED, Luquetti A, Shikanai-Yasuda MA, Coura JR, et al. $2^{\text {nd }}$ Brazilian Consensus on Chagas' Disease, 2015. Rev Soc Bras Med Trop. 2016;49 Suppl 1:3-60.

3. Zingales B. Trypanosoma cruzi genetic diversity: something new for something known about Chagas disease manifestations, serodiagnosis and drug sensitivity. Acta Trop. 2018;184:38-52. 4. Margioto Teston AP, Paula de Abreu A, Gruendling AP, Bahia
MT, Gomes ML, Marques de Araújo S, et al. Differential parasitological, molecular, and serological detection of Trypanosoma cruzi I, II, and IV in blood of experimentally infected mice. Exp Parasitol. 2016;166:44-50.

5. Umezawa ES, Bastos SF, Camargo ME, Yamauchi LM, Santos MR, Gonzalez A, et al. Evaluation of recombinant antigens for serodiagnosis of Chagas' disease in South and Central America. J Clin Microbiol. 1999;37:1554-60.

6. Carlier Y, Truyens C. Maternal-fetal transmission of Trypanosoma cruzi. In: Telleria J, Tibayrenc M, editors. American trypanosomiasis, Chagas disease: one hundred years of research. $2^{\text {nd }}$ ed. Amsterdam: Elsevier; 2017. p.517-59.

7. Esper HR, Freitas VL, Assy JG, Shimoda EY, Berreta OC, Lopes $\mathrm{MH}$, et al. Fatal evolution of acute Chagas disease in a child from Northern Brazil: factors that determine poor prognosis. Rev Inst Med Trop Sao Paulo. 2019;61:e27.

8. Brutus L, Castillo H, Bernal C, Salas NA, Schneider D, Santalla JA, et al. Detectable Trypanosoma cruzi parasitemia during pregnancy and delivery as a risk factor for congenital Chagas disease. Am J Trop Med Hyg. 2010;83:1044-7.

9. Rendell VR, Gilman RH, Valencia E, Galdos-Cardenas G, Verastegui M, Sanchez L, et al. Trypanosoma cruzi-infected pregnant women without vector exposure have higher parasitemia levels: implications for congenital transmission risk. PLoS One. 2015;10:e0119527.

10. Bittencourt AL, Sadigursky M, Silva AA, Menezes CA, Marianetti MM, Guerra SC, et al. Evaluation of Chagas's disease transmission through breast-feeding. Mem Inst Oswaldo Cruz. 1988;83:37-9.

11. Marcili A, Valente VC, Valente AS, Junqueira AC, Silva FM, Pinto AY, et al. Trypanosoma cruzi in Brazilian Amazon: lineages TCI and TCIIa in wild primates, Rhodinus spp, and in human with Chagas disease associated with oral transmission. Int $\mathbf{J}$ Parasitol. 2009;39:615-23

12. Monteiro WM, Magalhães LK, Sá AR, Gomes ML, Toledo MJ, Borges L, et al. Trypanosoma cruzi IV causing outbreaks of acute Chagas disease and infections by different haplotypes in the Western Brazilian Amazonia. PloS One. 2012;7:e41284

13. Carlyer Y, Torrico F. Congenital infection with Trypanosoma cruzi: from mechanisms of transmission to strategies for diagnosis and control. Rev Soc Bras Med Trop. 2003;36:76771.

14. de Rissio AM, Riarte AR, Garcia MM, Esteva MI, Quaglino M, Ruiz AM. Congenital Trypanosoma cruzi infection. Efficacy of its monitoring in an urban reference health center in a nonendemic area of Argentina. Am J Trop Med Hyg. 2010;82:83845.

15. Francisco-González L, Rubio-San-Simón A, González-Tomé MI, Manzanares A, Epalza C, Del Mar Santos M, et al. Congenital transmission of Chagas disease in a non-endemic area, is an early diagnosis possible? PLoS One. 2019;14:e0218491. 
16. Santana KH, Oliveira LG, Barros de Castro D, Pereira M. Epidemiology of Chagas disease in pregnant women and congenital transmission of Trypanosoma cruzi in the Americas: systematic review and meta-analysis. Trop Med Int Health. 2020;25:752-63.

17. Carlier Y, Altcheh J, Angheben A, Freilij H, Luquetti AO, Schijman AG, et al. Congenital Chagas disease: updated recommendations for prevention, diagnosis, treatment, and follow-up of newborns and siblings, girls, women of childbearing age, and pregnant women. PLoS Negl Trop Dis. 2019; 13:e0007694.

18. Colombo V, Giacomelli A, Casazza G, Galimberti L, Bonazzetti C, Sabaini F, et al. Trypanosoma cruzi infection in Latin American pregnant women living outside endemic countries and frequency of congenital transmission: a systematic review and meta-analysis. J Travel Med. 2021;28:taaa170.
19. Martins-Melo FR, Lima MS, Ramos Jr AN, Alencar CH, Heukelbach J. Prevalence of Chagas disease in pregnant women and congenital transmission of Trypanosoma cruzi in Brazil: a systematic review and meta-analysis. Trop Med Int Health. 2014;19:943-57.

20. Brasil. Ministério da Saúde. Secretaria de Vigilância em Saúde. Doença de Chagas: 14 de abril - Dia mundial. Brasília: Ministério da Saúde; 2020. [cited 2021 April 29]. Available from: https://antigo.saude.gov.br/images/pdf/2020/April/23/ boletim-especial-chagas-20abr20.pdf 